\title{
Long-term results of permanent memotherm urethral stent in the treatment of recurrent bulbar urethral strictures
}

\author{
Yusuf Ziya Atesci, Ayhan Karakose, Ozgu Aydogdu \\ Izmir University School of Medicine, Department of Urology, Izmir,Turkey
}

\section{ABSTRACT}

Purpose: To evaluate the long term outcomes of permanent Memotherm urethral stent in the treatment of recurrent bulbar urethral stricture.

Materials and Methods: Twenty patients who underwent permanent Memotherm urethral stent implantation due to recurrent bulbar urethral stricture following previous unsuccessful surgical procedure from 1996 to 2002 were included in the study. Long-term outcomes of the patients were evaluated.

Results: The overall success rate was $87.5 \%$ at the end of the tenth year. There was discomfort in implantation area in eight patients about 1 month following the procedure. These patients were treated with alpha-blocker and anti-inflammatory drugs. Stone formation was observed at the urethral stent implantation area in two patients. Post-void dripping has been observed in 15 patients up to the postoperative 3rd month. Stress urinary incontinence was observed in a patient with a 1-year follow-up. Partial stent migration was observed in two patients. None of the patients experienced pain during erection.

Conclusion: Memotherm urethral stent is a minimal invasive surgical procedure which can be safely and effectively used in patients with recurrent urethral stricture.

\section{ARTICLE INFO}

\section{Key words:}

Urethral Stricture; Stents;

Urinary Sphincter, Artificial

Int Braz J Urol. 2014; 40: 80-6

Submitted for publication:

April 17, 2013

Accepted after revision:

August 15, 2013

\section{INTRODUCTION}

Recurrent urethral stricture is one of the biggest problems in Urology. Internal urethrotomy, intermittant urethral dilatation and open urethroplasty in the treatment of urethral strictures may not give the desired result every time. This situation negatively affects the quality of life in patients with recurrent urethral stricture. As an alternative treatment to traditional methods urethral stents have been used since 1985 in the treatment of urethral strictures and successful results have been reported by many centers $(1,2)$.

We retrospectively evaluated the long term (10 years) outcomes of Memotherm permanent urethral stent.

\section{MATERIALS AND METHODS}

Twenty patients who were treated with Memotherm permanent urethral stent due to recurrent urethral stricture from 1996 to 2002 were included in the study. Memotherm is a thermoactive stent constructed of nitinol. Memotherm stent expands at body temperature and contracts at colder temperatures, so it is easy to remove. It is a wall rather than a mesh stent like the Urolume which might limit the hyperplastic reaction.

The mean age was 48 years (23-76) and the average length of the stricture was $2.5 \mathrm{~cm}$ (0.5-5.5) respectively. Mean duration of urethral stenosis was 3.7 years (1.3-6.2) and all patients experienced internal urethrotomy at least 3 times 
previous to urethral stent implantation. The mean follow-up was 12 (10-16) years. Demographic data of the patients are provided in Table-1.

Prior to surgery physical examination, urinalysis, routine serum tests, uroflowmetry, postvoiding residual urine volume measurement (PVR), retrograde urethrography, urethroscopy and ultrasound scan (US) of the urinary tract were performed. All patients used 2nd generation cephalosporins for prophylaxis.

In the first two patients the stent was placed gently in the urethra beginning $0.5 \mathrm{~cm}$ proximal to the stricture just after internal urethrotomy procedure under spinal anesthesia with 0 degree optical image. Urethrotomy was performed at 12 o'clock direction and we observed urethral stent migration through the internal urethrotomy incision in both patients. In our opinion the urethral tissue where the incision was performed was weak and epithelization had possibly occurred into the

Table 1 - Patients' characteristics and causes of urethral stenosis.

\begin{tabular}{lc}
\hline Mean age (year) & $48(23-76)$ \\
\hline mean stenosis duration (year) & $3.7(1.3-6.2)$ \\
The average length of stricture (cm) & $2.5(0.5-5.5)$ \\
The mean follow-up (year) & $12(10-16)$ \\
Previous failed surgeries & Number of patients (\%) \\
Internal urethrotomies & $16(80)$ \\
Open urethroplasty & $3(15)$ \\
Railroad catheterization & $1(5)$ \\
Etiology & Number of patients (\%) \\
Trauma & $9(45)$ \\
After endoscopic urethral venture & $7(25)$ \\
Post-infectious & $1(5)$ \\
Attempt wrong urethral catheter & $1(5)$ \\
\hline Idiopathic &
\end{tabular}

urethral stent causing a partial obstruction in the stent lumen and thus the urethral stent migrated through the weak tissue at 12 o'clock position. We thought that the migration rate could probably be decreased by urethral catheterization for a period of time allowing the re-epithelization of urethral tissue around the urethral catheter. Therefore we decided to change the subsequent surgical procedures. The latter 18 patients primarily underwent internal urethrotomy under spinal anesthesia and the patients maintained a urethral Foley catheter for two weeks following the procedure. At the postoperative 2nd week urethral catheter was removed and the stent was gently placed in the urethra beginning $0.5 \mathrm{~cm}$ proximal to the stricture with 0 degree optical image under local anesthesia in an outpatient basis. We performed the procedure under local anesthesia to see the voluntary contractions of external urethral sphincter and thus inserting urethral stent to the optimal position in the urethra. For the urethral stenosis close to the external urethral sphincter, care was taken during the stent implantation not to include the sphincter. No Foley catheter was inserted after the urethral stent placement. All patients were evaluated with uroflowmetry, PVR measurement, and urethroscopy (to evaluate stent epithelization) in the postoperative first month. All patients were followed at 3 months intervals for the first year than yearly. PVR, average $\left(Q_{\text {ave }}\right)$ and maximum urinary flow rate $\left(Q_{\text {max }}\right)$ values of the patients measured prior to the surgery, at the 1st and 10th year postoperatively are shown in Table- 2 .

Wilcoxon binary sample test was used for statistical analysis and $\mathrm{p}<0.05$ was considered to indicate statistical significance.

\section{RESULTS}

The mean age of the patients was 48 (2376) years. Patients were followed for an average 12 (10-16) years. The stent was placed under spinal anesthesia in the first two patients. But the stents migrated. These stents were positioned using repositioning forceps. The stent was placed under local anesthesia in the latter 18 patients. None of these patients had stent migration after the surgical procedure was modified as explained previously. 
Table 2 - Uroflowmetry and PVR measurements preoperatively, at the postoperative 1st and 10th year.

\begin{tabular}{lcccc}
\hline & Preoperative & 1-year follow-up & 10-year follow-up & $p$ value \\
\hline Mean $Q_{\text {max }}(\mathrm{mL} / \mathrm{s})$ & $6.9(4-11)$ & $23.7(14-32)$ & $22.4(13-33)$ & $<0.05$ \\
Mean Qaverage $(\mathrm{mL} / \mathrm{s})$ & $3.7(2-5)$ & $11.2(8-14)$ & $10.5(7-13)$ & $<0.05$ \\
PVR $(\mathrm{mL})$ & $190(100-330)$ & $37(0-50)$ & $22(0-80)$ & $<0.05$ \\
\hline
\end{tabular}

The mean preoperative $Q_{\max }$ was 6.9(4-11) $\mathrm{mL} / \mathrm{s}, \mathrm{Q}_{\text {ave }} 3.7(2-5) \mathrm{mL} / \mathrm{s}$ and PVR was $190(100-$ 330) $\mathrm{mL}$. The mean $\mathrm{Q}_{\max }$ was $23.7(14-32) \mathrm{mL} / \mathrm{s}$ and $22.4(13-33) \mathrm{mL} / \mathrm{s}$, the mean $\mathrm{Q}_{\text {ave }}$ was $11.2(8-$ 14) $\mathrm{mL} / \mathrm{s}$ and $10.5(7-13) \mathrm{mL} / \mathrm{s}$, the mean PVR was $37(0-50) \mathrm{mL}$ and $22(0-80) \mathrm{mL}$ at the 1 st and 10 th year follow-up, respectively. The data are summarized in Table-2.

The urethral opening was obtained in 18 of 20 patients (90\%) at the end of the first year following single procedure (Figure-1). Secondary stent implantation was performed in two patients. None of our patients underwent neither internal urethrotomy or transurethral resection for hyperplastic reaction. The stone formation occured at urethral stent implantation area in two patients (Figure-2). These stones were fragmented using endoscopic lithotripsy. The stents were observed as re-epithelialized in the 2nd month after the stones have been fragmented and no patients experienced extraction of the stent due to stone formation. Partial stent migration was observed in two patients. Firstly the urethra was irrigated with cold saline and then these stents were repositioned using re-positioning forceps. Eight patients experienced discomfort in the implantation area at the first month following the procedure. These patients were treated with alpha-blockers and anti-inflammatory drugs. No stent extraction was performed due to discomfort in the implantation area. Fifteen patients have experienced post-voiding dripping for 3 months following the stent placement procedure. But post-voiding dripping decreased in 10 patients by the 10 -year follow-up. Stress urinary incontinence was observed in one patient with a 1-year follow-up. None of the patients presented with pain during erection. Complications are listed in Table-3. The overall success rate was $87.5 \%$ at the postoperative 10th year.

\section{DISCUSSION}

Despite the advances in technology endoscopic treatment of urethral stenosis still does not have the desired outcomes. Frequent recurrence of stenosis and lack of curative treatment

Figure 1 - Appearance of the urethra at the postoperative 1st and 10th year respectively.
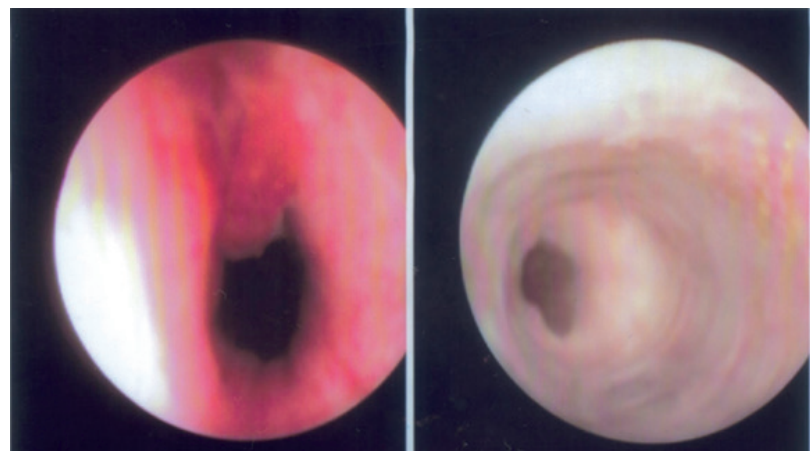

Figure 2 - Stone formation in implantation area.

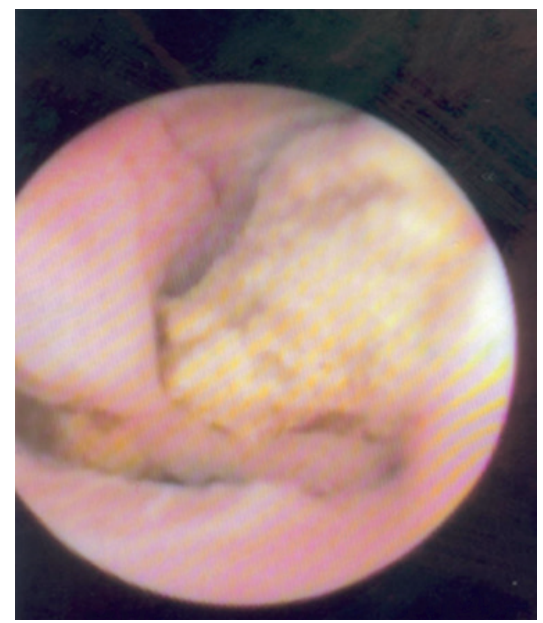


Table 3 - Complication rates.

\begin{tabular}{lc}
\hline & Number of patients (\%) \\
\hline Discomfort in implantation area & $8(40)$ \\
Partial stent migration & $2(10)$ \\
Stone formation in implantation area & $2(10)$ \\
Dripping after micturition & $15(75)$ \\
\hline
\end{tabular}

have a negative impact on patients' psychology. The long-term treatment success rate is $20-45 \%$ after the first internal urethrotomy. Success rate after urethroplasty using a variety of techniques is up to $90-95 \%$. However, urethroplasty success rate decreases to $40 \%$ in complex urethral strictures (3). Due to low success rates of internal urethrotomy and difficulty in the urethroplasty technique, clinicians searched for alternative methods which can be used in the treatment of urethral strictures including metallic urethral stents (Urolume, Memotherm) (4).

Milroy et al. reported a 63\% success rate at long term follow-up of the permanently implantable 'Urolume' stent in 1993 (5). Also Sertcelik et al. reported their clinical experience with Urolume in 2000 . In that study they reported an $87 \%$ success rate at a mean of 3.8-year follow-up in 60 patients who had recurrent bulbar urethral stenosis (6).

Memotherm is a thermoactive stent constructed of nitinol. Memotherm can be extracted easily and repositioned since it does not stick to the tissue. Ponce et al. have achieved complete success in four patients with complicated urethral stenosis using Memotherm metalic stent with long-term follow-up (7).

In the present study Memotherm stent has been inserted immediately after internal urethrotomy operation in the first two patients and stent migration has been observed following the procedure. Urethrotomy was performed at 12 o'clock direction and we observed urethral stent migration through the internal urethrotomy incision in both patients. In our opinion the urethral tissue where the incision was performed was weak and epithelization possibly occurred into the urethral stent causing a partial obstruction in the stent lumen and thus the urethral stent migrated through the weak tissue at 12 o'clock position. We thought that the migration rate could probably be decreased by urethral catheterization for a period of time allowing the re-epithelization of urethral tissue around the urethral catheter. Therefore we decided to change the subsequent surgical procedures. The surgical method has been modified and eighteen patients underwent Memotherm stent insertion observing the voluntary contractions of external urethral sphincter. At the postoperative 2 nd week urethral catheter was removed and the stent was gently placed in the urethra beginning $0.5 \mathrm{~cm}$ proximal to the stricture with 0 degree optical image under local anesthesia in an outpatient basis. We performed the procedure under local anesthesia to see the voluntary contractions of external urethral sphincter and thus inserting urethral stent to the optimal position in the urethra. No stent migration has been observed in these 18 patients. In contrast with the previous studies, none of our patients presented with partial migration after the surgical procedure has been changed $(3,7,8)$. We think that stent implantation should be performed at least 2 weeks following the internal urethrotomy procedure to achieve optimal epithelization. The high success rate (87.5\%) presented here was probably due to the modified surgical procedure which was explained above. In the present study eight patients reported discomfort in the implantation area in the first postoperative month and the patients were treated with alpha-blocker and anti-inflammatory drugs. In contrast with the previous studies, none of our patients experienced the extraction of the stent due to discomfort in the implantation area (3).

Two patients presented with stone formation in the implantation area during the follow-up and the patients were treated with endoscopic stone fragmentation. None of the patients underwent stent extraction following the endoscopic fragmentation of the urethral stones. At urethroscopy performed in the first month following the endoscopic stone fragmentation, sufficient urethral opening and epithelization over the stent was observed. In our experience we observed that 
stent extraction is not necessary for the endoscopic treatment of urethral stones. To the best of our knowledge this is the first study reporting stone formation in the implantation area.

None of our patients underwent neither internal urethrotomy nor transurethral resection for hyperplastic reaction. Post-voiding dripping which has been observed in 15 patients, continued up to 3 months after the stent placement. But this decreased in 10 patients by the 10-year follow-up. In reviewing the literature, this may be due to post-voiding of urine accumulated in the stent (8). The rate of dripping after micturition decreased after stent epithelization in the long-term follow-up (3).

In the present study the mean preoperative $Q_{\max }$ was 6.9(4-11) $\mathrm{mL} / \mathrm{s}, Q_{\text {ave }} 3.7(2-5) \mathrm{mL} / \mathrm{s}$ and PVR was 190 (100-330) $\mathrm{mL}$. The mean $\mathrm{Q}_{\max }$ was $23.7(14-32) \mathrm{mL} / \mathrm{s}$ and $22.4(13-33) \mathrm{mL} / \mathrm{s}$, the mean $\mathrm{Q}_{\text {ave }}$ was $11.2(8-14) \mathrm{mL} / \mathrm{s}$ and $10.5(7-13) \mathrm{mL} / \mathrm{s}$, the mean PVR was 37(0-50) $\mathrm{mL}$ and 22(0-80) $\mathrm{mL}$ at the 1- and 10-year follow-up, respectively. Sertcelik et al. reported the mean PVR in patients with urethral stenosis as $210(100-350) \mathrm{mL}$, and at 1 and 7 years after stent placement it was 36 (0-700) $\mathrm{mL}$ and 27.5 (0-100) $\mathrm{mL}$, respectively. They also reported the $Q_{\max }$ before stent placement as 6.8 (410) $\mathrm{mL} / \mathrm{s}$ and at 1 and 7 years after stent placement it was $22.4(16-33) \mathrm{mL} / \mathrm{s}$ and $22.2(12-35)$ $\mathrm{mL} / \mathrm{s}$, respectively (3). Ricciotti et al. reported the mean $Q_{\max }$ as $24.4(18-33) \mathrm{mL} / \mathrm{s}$ and the PVR was $36(0-80) \mathrm{mL}$ at 6 months after the stent placement. They also reported complete epithelization in 20 of 21 patients with recurrent urethral stenosis and $18 \mathrm{~F}$ urethral calibration at the 6-month follow-up (9).

Since the study presented here is retrospective and non-randomized, it can potentially have selection bias. In addition, the number of patients included in the study is relatively low to support the usefulness and efficacy of a modified surgical technique. All patients presented here had bulbar urethral stricture and we couldn't make a comparison between patients who had urethral strictures in different localizations including penile, bladder neck etc. Further high numbered, prospective and randomized studies are necessary to support our findings.
In conclusion we assessed the Memotherm urethral stent implantation in the treatment of recurrent bulbar urethral stricture. Memotherm stent expands at body temperature and contracts at colder temperatures, so it is easy to remove. It is a wall rather than a mesh stent like the Urolume which might limit the hyperplastic reaction. In spite of various opinions about the treatment of patients with recurrent urethral stricture, in our opinion urethral stent implantation is a minimal invasive technique that can be safely and effectively used as a primary surgical procedure in the treatment of recurrent urethral stricture. Urethral stent implantation should be the preferred method after two consecutive unsuccessful internal urethrotomy procedures. In our experience implantation of the stent using the surgical technique explained at least 2 weeks following the internal urethrotomy procedure would potentially increase the success rates. This finding should be supported with further prospective and randomized studies.

\section{CONFLICT OF INTEREST}

None declared.

\section{REFERENCES}

1. Braf Z, Chen J, Sofer M, Matzkin H: Intraprostatic metal stents (Prostakath and Urospiral): more than 6 years' clinical experience with 110 patients. J Endourol. 1996; 10: 555-8.

2. Parikh AM, Milroy EJ: Precautions and complications in the use of the urolume wallstent. Eur Urol. 1995; 27: 1-7.

3. Sertcelik MN, Bozkurt IH, Yalcinkaya F, Zengin K: Long-term results of permanent urethral stent Memotherm implantation in the management of recurrent bulbar urethral stenosis. BJU Int. 2011; 108: 1839-42.

4. Milroy EJ, Chapple C, Eldin A, Wallsten H: A new treatment for urethral strictures: a permanently implanted urethral stent. J Urol. 1989; 141: 1120-2.

5. Milroy E, Allen A: Long-term results of urolume urethral stent for recurrent urethral strictures. J Urol. 1996; 155: 904-8.

6. Sertcelik N, Sagnak L, Imamoglu A, Temel M, Tuygun C: The use of self-expanding metallic urethral stents in the treatment of recurrent bulbar urethral strictures: long-term results. BJU Int. 2000; 86: 686-9. 
7. Ponce Campuzano A, González Satué C, Rodríguez Tolrà J, Trilla Herrera E, Serralach i Milà N: Treatment of urethral stenosis with thermo-expandable prosthesis "Memotherm". Our experience. Arch Esp Urol. 2000; 53: 253-8.

8. Gottfried HW, Schlmers HP, Gschwend J, Brändle E, Hautmann RE: Thermosensitive stent (Memotherm) for the treatment of benign prostatic hyperplasia. Arch Esp Urol. 1994; 47: 933-43; discussion 943-6.
9. Ricciotti G, Bozzo W, Perachino M, Pezzica C, Puppo P: Heatexpansible permanent intraurethral stents for benign prostatic hyperplasia and urethral strictures. J Endourol. 1995; 9: 417-22.

Correspondence address:

Ayhan Karakose, MD Department of Urology, Izmir University School of Medicine, Izmir,Turkey

Telephone: + 90232 399-5050 E-mail: drayhankarakose@gmail.com 


\section{EDITORIAL COMMENT}

This is an important article that certainly adds to existing knowledge about the long term results of permanent memotherm urethral stent for urethral strictures. Urologists have to deal with scarce specific data to make projections about clinical evolution of these complex situations. The current paper assesses the feasibility of the procedure and the (satisfying) outcome for most of the patients. Interestingly, stone for-

\section{REFERENCES}

1. Barbagli G, Sansalone S, Djinovic R, Romano G, Lazzeri M: Current controversies in reconstructive surgery of the anterior urethra: a clinical overview. Int Braz J Urol. 2012; 38: 307-16; discussion 316. mation in the stent area was first described for nitinol urethral devices. Unfortunately, the long term evolution after stone removal was not described, since follow-up was restricted to a month period.

Currently there is no consensus among researchers on which intervention is best for urethral stricture disease in terms of results, and also costs and adverse effects (1). Undoubtely, memotherm stent is a valid alternative in cases that have had previous failed surgical procedures.
Daniel Xavier, MD

Clinical Hospital UFMG Professor Alfredo Balena, 110 Santa Efigênia, Belo Horizonte, MG, Brazil 